\title{
A Systematic Review and Meta-Analysis Study to Investigate the Prevalence of Helicobacter pylori and the Sensitivity of its Diagnostic Methods in Iran
}

\author{
Fatemeh Sayehmiri ${ }^{1}$;Zahra Darvishi ${ }^{1}$;Kourosh Sayehmiri ${ }^{2}$; Setareh Soroush $^{3,4}$;Mohammad \\ Emaneini ${ }^{3}$; Raffaele Zarrilli ${ }^{5}$; Morovat Taherikalani ${ }^{4,}$ \\ ${ }^{1}$ Student Research Commitee, Ilam University of Medical Sciences, Ilam, IR Iran \\ 2 Prevention of Psychosocial Injuries Research Center, Ilam University of Medical Sciences, Ilam, IR Iran \\ ${ }^{3}$ Department of Microbiology, School of Medicine, Tehran University of Medical Sciences, Tehran, IR Iran \\ ${ }_{5}^{4}$ Clinical Microbiology Research Center, Ilam University of Medical Sciences, Ilam, IR Iran \\ ${ }^{5}$ Clinical Microbiology Research Center, Ilam University of Medical Sciences, \\ ${ }^{*}$ Corresponding Author: Morovat Taherikalani, Department of Medical Microbiology, Clinical Microbiology Research Center, Ilam University of Medical Sciences, Ilam, IR Iran. Tel: \\ +98-9126501584, E-mail: taherikalani@gmail.com
}

Received: May 29, 2013; Revised: December 14, 2013; Accepted: April 27, 2014

\begin{abstract}
Context: Helicobacter pylori is the most common infecting organism affecting humans, being almost half the population infected. The aim of this study was to find out the epidemiological features and the sensitivity of diagnostic methods of Helicobacter pylori infection in Iran, which can provide the logic of developing preventive approaches to control Helicobacter pylori infections and the associated diseases. Evidence Acquisition: By reviewing the databases of SID, MAGIRAN, SCOPUS, MEDLIB, Google, ISI and PUBMED, a total of 30 papers, published from 1994 to 2011, were extracted. Summary prevalence and 95\% confidence intervals (95\% CI) were calculated using randomeffects model. Statistical analyses were performed using STATA Ver.11.

Results: Among the 30 studies evaluated, the prevalence rate of Helicobacter pylori infections in Iran was estimated as 50.7\% (95\% CI: 44.4$56.9 \%$ ). When the sensitivity of diagnostic methods was evaluated, ELISA, with an accuracy rate of $52.3 \%$ (95\% CI: 43.8 to $60.8 \%$ ) was found the most accurate diagnostic method available. The highest and the least Helicobacter pylori prevalence were $19.2 \%$ in Tehran and $74.27 \%$ in Mazandran respectively.

Conclusions: About half the population in Iran is infected with Helicobacter pylori, the pollution in different areas and preventive strategies should be carried out to control this infection. The prevalence rate of Helicobacter pylori infections in Iran showed only little changes during the years 1994 to 2011.
\end{abstract}

Keywords:Helicobacter pylori; Prevalence; Meta-analysis; Iran

\section{Context}

Almost half the population in the world is infected by $H$. pylori which is the most common infecting organism affecting humans $(1,2)$. Since the first experience of Helicobacter culture in 2004 by Marshall and Warren, a considerable amount of information has been acquired on clinical aspects of this infection (3). Helicobacter pylori is tightly associated with gastro-intestinal disorders, some important consequences of which can be chronic gastritis, peptic ulcer leading to gastric cancer, indigestion and non-ulcer dyspepsia (4-9).

In developing countries, the prevalence of $H$. pylori positive serology during childhood is higher than that in developed countries. This is vice versa during adulthood $(10,11)$. In a Meta-analysis study, the prevalence of $H$. pylori infection in China was reported as $58.07 \%$ (12). In another Meta-analysis study, the association between $H$. pylori infection and the risk of esophageal cancer (EAC) has been suggested (13). Also, the association between $H$. pylori infection in diabetic and non-diabetic individuals with dyspepsia was assessed. This study showed that the prevalence of $H$. pylori infection was considerably higher in diabetic patients compared to non-diabetic individuals $(\mathrm{P}=0.001)$. According to these results, diabetes Mellitus is one of the risk factors that need attention in the evaluation of $H$. pylori infections among diabetic patients with dyspepsia (14).

The prevalence of $H$. pylori infection was 58\% among residents of two villages in Northern Italy, considerably higher than the $34 \%$ observed in an earlier similar study of adults in northern Swedish communities (mean age = 52 years). A prevalence of $60 \%$ or more was reported for groups in Albania, Egypt, Iran, Turkey, and China (15). The prevalence of $H$. pylori infection was 3.0\% among index children at age 4 and maternal infection was the only risk factor at multivariate analysis (16).

One of the main objectives of Meta-analysis studies,

Implication for health policy/practice/research/medical education:

This is the first systematic review and meta-analysis on prevalence of $H$. pylori in Iran that prepared in collaboration with Dr. Raffaele Zarrilli in Italy. In this review, we used nearly all of the papers published in Persian and English languages.

Copyright (c) 2014, Iranian Red Crescent Medical Journal; Published by Kowsar Corp. This is an open-access article distributed under the terms of the Creative Commons Attribution License, which permits unrestricted use, distribution, and reproduction in any medium, provided the original work is properly cited. 
which are a combination of different studies, is to reduce the difference between parameters as a result of an increase in the number of studies involved in the process of analysis and also to reduce the confidence level of these measures/figures.

The aim of this study was to investigate the studies carried out on the prevalence of $H$. pylori infection in Iran and to estimate the prevalence rate of this infection according to diagnostic methods, age group of individuals infected, gender, infection age and additional parameters.

\section{Evidence Acquisition}

This study was a systematic review and a Meta-analysis study on the prevalence of Helicobacter in Iran. The findings of this research were based on the papers published in internal and external journals. The papers were selected from the databases of SID, MAGIRAN, SCOPUS, MEDLIB, Google, ISI and PUBMED. Searching of the articles was carried out using the key words: Helicobacter, prevalence, and a combination of these words. To decrease bias two authors (Sayehmiri F, Darvishi Z) did search, selection of papers and extracting data of articles independently. First, all the articles related to Helicobacter pylori in Iran were collected. At this stage, the articles possessing the relevant key words in their title or abstract were entered into the list, excluding all the other articles not relevant to the prevalence of $H$. pylori. A check list of necessary information was prepared that included: title of the article, location of the study, location of sampling, sample volume, the methods of assessing infection, the mean age of individuals infected by $H$. pylori and the total prevalence of $H$. pylori.

According to the protocol, a total of 142 articles that were carried out from 1994 to 2011 were analyzed during the primary research. The abstracts of 94 articles, out of the 142, were then analyzed and a complete review of 45 of these papers, that included the basic information required, was then carried out. Due to unavailability of the prevalence rates, some articles were omitted and a total of 30 articles were finally entered into the process of analysis (17-46) (Figure 1 the study flowchart).

\subsection{Statistical Analysis}

The variance of each study was calculated according to the binomial distribution. The studies were combined together according to sample size and variance. Because of the study heterogeneity, random-effect model was used to combine the studies. To assess the heterogeneity of the studies, Cochrane $\mathrm{Q}$ test and the $\mathrm{I}^{2}$ index were used. P-value of less than $5 \%$ was considered as significant in the heterogeneity test. To investigate the relationship between years of study and sample size meta-regression model was used.

Furthermore, considering the type of data analyzed, which were all prevalence rates, there was no need to determine the publication bias and to draw a funnel plot. The data were analyzed using STATA version 11.2.

\section{Results}

In the 30 papers assessed, the prevalence rate of Helicobacter pylori infection in Iran was estimated as 50.7\% (95\% CI: 44.4-56.9\%) (Figure 2). The lowest prevalence rate (19.2\%) was related to a study in Mazandaran province, the city of Sari and the highest prevalence rate (74.27\%) were reported in a study in Tehran province, the city of Tehran. Details of the papers analyzed are found in Table 1.

In one classification, analysis was carried out based on the diagnostic methods. The sensitivity level of ELISA, according to this analysis, was estimated as 52.3\% (95\% CI: 43.8 60.8 ), the sensitivity of the urease method as $51.9 \%$ (95\% CI: 36.9-66.9) and other diagnostic methods including touch cytology, histopathology as $45.8 \%$ (95\% CI: 31.3-60.4). These results show that ELISA and urease are relatively more accurate methods to diagnose H. pylori infection (Table 2).

In another classification, the individuals under assay were divided into the two groups of symptomatic and nonsymptomatic individuals. The prevalence rate of infection among individuals with digestive disease symptoms, with a sample size of 1873 individuals, was estimated as 47.6\% (95\% CI:56.1-39.2) and among healthy individuals, with a sample size of 7131 individuals, as 53.1\% (95\% CI: 45.4-60.8). Based on gender, the prevalence rate was estimated as $37.7 \%$ (95\% CI: 95\% CI: 27.5-48) in females and 35.7\% (95\% CI: 19.6-51.7) in males. In analysis based on the age groups, the prevalence rate among the age group below 20 years was estimated as 38.3\% (95\% CI: 28.1-48.5), among the age group between 2040 years as $50.3 \%$ ( $95 \% \mathrm{CI}: 39.5-61)$ and among the age group above 40 as $60.1 \%$ (95\% CI: 52.4-67.8). In this analysis, a significant difference was found among the three age groups which can be evidence to the conclusion that the rate of $H$. pylori infection increases as the age increases (Table 3 ).

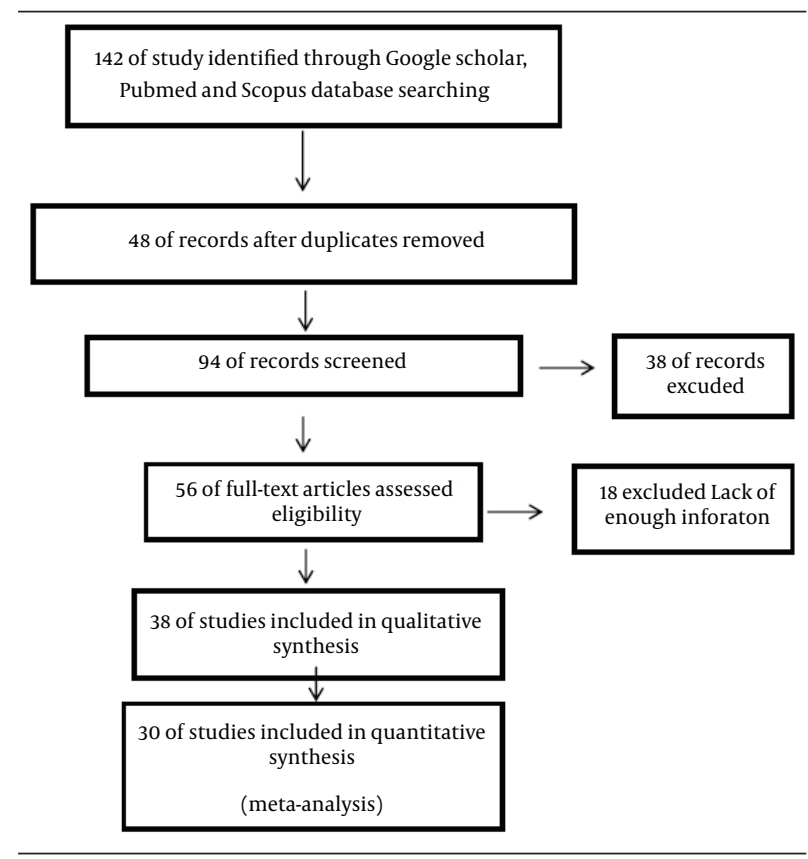

Figure 1. Study Flowchart 
Study

ID
$\%$

ES $(95 \% \mathrm{Cl}) \quad$ Weight

\begin{tabular}{|c|c|c|c|}
\hline Kerman (1993) & $1 \rightarrow$ & $0.57(0.53,0.61)$ & 3.51 \\
\hline Semnan (1999) & - & $0.48(0.44,0.52)$ & 3.52 \\
\hline Kashan (2000) & $\longrightarrow$ & $0.31(0.16,0.45)$ & 2.99 \\
\hline Sari (2000) & $\rightarrow$ & $0.19(0.15,0.23)$ & 3.52 \\
\hline Sari (2001) & i & $0.64(0.60,0.69)$ & 3.49 \\
\hline Tehran (2001) & $i$ & $0.57(0.47,0.67)$ & 3.28 \\
\hline Tehran (2001) & $\frac{1}{T}$ & $0.58(0.47,0.70)$ & 3.19 \\
\hline Ghazvin(2002) & -1 & $0.44(0.35,0.52)$ & 3.34 \\
\hline Tehran (2002) & i & $0.68(0.60,0.77)$ & 3.35 \\
\hline Ghazvin(2002) & 1 & $0.80(0.72,0.87)$ & 3.40 \\
\hline Tehran (2002) & I & $0.60(0.56,0.64)$ & 3.51 \\
\hline Esfahan(2002) & + & $0.44(0.33,0.56)$ & 3.17 \\
\hline Tehran (2003) & $\rightarrow$ & $0.29(0.23,0.36)$ & 3.42 \\
\hline Tehran (2003) & i & $0.70(0.57,0.83)$ & 3.11 \\
\hline Mashhad (2004) & 1 & $0.63(0.56,0.69)$ & 3.42 \\
\hline Yazd(2004) & $\frac{1}{1}$ & $0.44(0.25,0.62)$ & 2.73 \\
\hline Tehran(2004) & & $0.58(0.47,0.69)$ & 3.22 \\
\hline Gilan (2004) & . & $0.54(0.40,0.68)$ & 3.04 \\
\hline Gilan (2005) & $\sim 1$ & $0.40(0.37,0.43)$ & 3.53 \\
\hline Tehran(2006) & $\bullet$ & $0.26(0.24,0.28)$ & 3.55 \\
\hline Kordestan (2006) & $\downarrow$ & $0.37(0.34,0.39)$ & 3.55 \\
\hline Tehran (2006) & $\rightarrow \quad$ & $0.36(0.28,0.43)$ & 3.39 \\
\hline Mashhad (2006) & $\rightarrow \quad$ i & $0.35(0.28,0.42)$ & 3.42 \\
\hline Kashan (2007) & 1 & $0.66(0.57,0.75)$ & 3.31 \\
\hline Tabriz (2009) & - & $0.52(0.43,0.61)$ & 3.32 \\
\hline Tehran (2010) & 1 & $0.74(0.69,0.79)$ & 3.49 \\
\hline Esfahan (2010) & i & $0.30(0.21,0.39)$ & 3.32 \\
\hline Tabriz (.) & 1 & $0.72(0.64,0.80)$ & 3.37 \\
\hline Tabriz (.) & $T$ & $0.43(0.32,0.53)$ & 3.24 \\
\hline Tabriz (.) & $1-$ & $0.65(0.55,0.74)$ & 3.29 \\
\hline Overall $($ l-squared $=97.4 \%, p=0.000)$ & & $0.51(0.44,0.57)$ & 100.00 \\
\hline NOTE: Weights are from random effects analysis & I & & \\
\hline$T$ & \multicolumn{3}{|c|}{.867} \\
\hline
\end{tabular}

According to the year and the location of studies assessed. The midpoint of each line illustrates the prevalence rate estimated in each study. The diamond sign shows the prevalence rate throughout the country for all the studies.

The Figure 3 shows the relationship between the prevalence of $H$. pylori infection and year of study, and sample size using meta regression models. In Figure 3 A the negative slope of the meta regression line showed that the prevalence of $H$. pylori infection in Iran has had a decreasing trend with a slow slop but it was not significant. In Figure $3 \mathrm{~B}$ the relation between sample size was compared to the prevalence rate of $H$. pylori infection and according to this figure there isn't a significant relation between the sample size and prevalence $(\mathrm{P}=0.06)$. At the following figure the circles show the weight of studies and it seems that studies with greater sample sizes are more prevalent and vice versa (Figure 3 ). In the Table 4 , a summary of data related to meta-regression curves are shown. 
Sayehmiri F et al.

\begin{tabular}{|c|c|c|c|c|c|c|c|c|}
\hline \multirow{2}{*}{$\begin{array}{l}\text { City } \\
\text { Kashan }\end{array}$} & \multirow{2}{*}{\begin{tabular}{|l} 
year \\
2000
\end{tabular}} & \multirow{2}{*}{$\begin{array}{c}\text { Age,y } \\
4.1 \pm 9.9\end{array}$} & \multirow{2}{*}{$\begin{array}{c}\begin{array}{c}\text { Sample } \\
\text { Size }\end{array} \\
39\end{array}$} & \multirow{2}{*}{$\begin{array}{c}\begin{array}{c}\text { Diagnostic } \\
\text { Method }\end{array} \\
\text { Urease }\end{array}$} & \multirow{2}{*}{$\begin{array}{c}\text { Prevalence } \\
30.8\end{array}$} & \multicolumn{2}{|c|}{$\mathbf{9 5} \% \mathrm{CI}$} & \multirow{2}{*}{$\begin{array}{c}\text { References } \\
\text { Taghavi et al. (30) }\end{array}$} \\
\hline & & & & & & 45.3 & 16.3 & \\
\hline Sari & 2000 & $7-18$ & 400 & - & 19.2 & 23.1 & 15.3 & Tergar Fakheri et al.(39) \\
\hline Semnan & 1999 & & 700 & Elisa & 48 & 57.1 & 44.3 & Moradi et al .(22) \\
\hline Ghazvin & 2002 & 54.4 & 125 & Urease & 43.7 & 52.4 & 35 & Hajagamohammadi et al. (17) \\
\hline Sari & 2001 & & 394 & Elisa & 64.2 & 69.1 & 59.7 & Baba mahmoodi et al. (38) \\
\hline $\begin{array}{l}\text { Khorasan } \\
\text { razavi }\end{array}$ & 2004 & $12-75$ & 195 & Urease & 62.56 & 69.4 & 55.8 & Nakhaei Moghadam et al. (40) \\
\hline Tehran & 2002 & 30.65 & 120 & Urease & 68.3 & 76.6 & 60 & Faghihi et al. (23) \\
\hline Yazd & 2004 & $30-65$ & 28 & - & 43.5 & 61.9 & 25.1 & Benesh et al. (41) \\
\hline Ghazvin & 2002 & $10-60$ & 240 & Elisa & 2000.5 & 86.7 & 1993.3 & Sheikholslami et al. (18) \\
\hline Tabriz & 2009 & $3.21 \pm 8.38$ & 116 & Serology & $\begin{array}{l}\text { Children } 60.3 \text {, Moth- } \\
\text { ers } 57.8 \text {, Fathers } 37.9\end{array}$ & 61.1 & 42.9 & Rafiei et al. (31) \\
\hline Kerman & 1993 & 57.05 & 513 & Urease & 56.9 & 61.2 & 52.6 & Zojajy (19) \\
\hline Tehran & 2002 & $8.8 \pm 48$ & 576 & Endoscopy & 59.7 & 63.7 & 55.7 & Yasseri (24) \\
\hline Tehran & 2004 & $2.2 \pm 24$ & 137 & Elisa & 65.57 & 75.3 & 56.7 & Sharifian et al. (32) \\
\hline Tehran & 2004-2006 & $6-12$ & 1665 & Urease & 26 & 28.1 & 23.9 & Zamani et al.(25) \\
\hline Tehran & 2003 & - & 170 & Histopathology & 29.4 & 36.2 & 22.6 & Barati et al. (26) \\
\hline Tabriz & - & - & 120 & - & 71.6 & 2000.7 & 63.5 & Rahnama et al. (43) \\
\hline Tabriz & - & - & 86 & - & 42.6 & 53.1 & 32.1 & Rafeey et al. (44) \\
\hline Tabriz & 2003 & $0.03 \pm 8.3$ & 96 & - & 64.6 & 74.2 & 55 & Modaresi et al. (45) \\
\hline Kurdistan & 2006 & $\begin{array}{c}14.91 \pm \\
15.32\end{array}$ & 1503 & Elisa & 36.5 & 38.9 & 34.1 & Yazdanpanah et al. (33) \\
\hline Tehran & 2006 & 39 & 152 & - & 35.52 & 43.1 & 27.9 & Shokohizadeh et al. (46) \\
\hline Tehran & 2010 & 43.9 & 311 & - & 74.27 & 2000.1 & 69.4 & Neshandar et al. (34) \\
\hline Kashan & 2007 & $17.13 \pm 43.3$ & 100 & Elisa & 66 & 75.3 & 56.7 & Arj et al. (20) \\
\hline Tehran & 2003 & $\begin{array}{c}11.67 \pm \\
39.68\end{array}$ & 50 & $\begin{array}{l}\text { Urease, IgG, } \\
\text { Histology }\end{array}$ & 70 & 2003.7 & 57.3 & Baghaei et al. (42) \\
\hline Isfahan & 2010 & $16-62$ & 100 & PCR & 30 & 39 & 21 & Salehi et al.(27) \\
\hline Guilan & 2004 & $\begin{array}{c}11.30 \pm \\
32.38\end{array}$ & 50 & Elisa & 54 & 67.8 & 40.2 & Ghanei et al.(28) \\
\hline Tehran & 2001 & & 100 & $\begin{array}{l}\text { Urease, Pathol- } \\
\text { ogy }\end{array}$ & 57 & 66.7 & 47.3 & Gottaslou et al. (29) \\
\hline Guilan & 2005 & $7-11$ & 961 & Elisa & 40 & 43.1 & 36.9 & Mansor et al. (35) \\
\hline Tehran & 2001 & 48.3 & 1993 & Citology & 58.3 & 69.7 & 46.9 & Vahidi et al. (36) \\
\hline Isfahan & 2002 & & 70 & Elisa & 44.44 & 56.1 & 32.8 & Sanei et al. (21) \\
\hline $\begin{array}{l}\text { Khorasan } \\
\text { razavi }\end{array}$ & 2006 & $\begin{array}{l}4.77 \pm \\
23.50\end{array}$ & 187 & Elisa & 34.7 & 41.5 & 27.9 & Dolatian et al. (37) \\
\hline - & - & - & - & - & 50.7 & 56.9 & 44.4 & - \\
\hline
\end{tabular}


To assess publication bias we used funnel plot (Figure 4) that it showed there was a significant publication bias $(\mathrm{P}=0.016)$. In another classification, the analysis was carried out based on the city of the study, according to which the highest prevalence rate (61.7\%), with a sample size of 245 individuals, was related to Ghazvin province (95\% CI: 26.6-96.8) and the lowest prevalence rate (36.5\%), with a sample size of 73 individuals, was related to Kurdistan province (95\% CI: 38.9-34.1) (Table 5).

\section{Discussion}

A data containing 9198 Helicobacter pylori-infected indi- viduals were included in the current study. A total of 30 papers were entered into the final Meta-analysis. $I^{2}$ statistics showed a high variation among studies results $\left(\mathrm{I}^{2}=\right.$ $97.4, \mathrm{P}=0.000)$. In three studies, including those carried out in Gilan, Sari and Qazvin, sampling had been carried out in villages as well as in cities $(17,33,38)$. The prevalence rate of $H$. pylori was calculated for all the individuals in all the age groups, based on the status of the individuals, gender and age groups.

In our review, random effect models were used for metaanalysis, considering the possibility of significant heterogeneity between studies which was tested with the Q test.

\begin{tabular}{lcc}
\hline Table 2. Prevalence Rate of H. pylori Infection in Iran According to Different Diagnostic Methods & \\
\hline Diagnostic Methods & Study, No. & H. pylori, \%, 95\% CI \\
\hline Total Recognize group & 30 & $50.7(44.4-56.9)$ \\
\hline ELISA & 10 & $52.3(43.8-60.8)$ \\
\hline Urease test & 8 & $51.9(36.9-66.9)$ \\
\hline Other methods & 5 & $45.8(31.3-60.4)$ \\
\hline & Study, No. & \\
\hline Table 3. Prevalence Rate of H.pylori Infection in Iran According to Health Status, Age and Gender & H. pylori, \%, 95\% CI \\
\hline & 30 & $50.7(44.4-56.9)$ \\
\hline Total & - & - \\
\hline Sex & 5 & $37.7(27.5-48)$ \\
\hline Women & 5 & $35.7(19.6-51.7)$ \\
\hline Men & - & - \\
Population & 17 & $47.6(39.2-56.1)$ \\
\hline Patient & 13 & $53.1(45.4-60.8)$ \\
\hline Healthy & - & $38.3(28.1-48.5)$ \\
Age, $y$ & 6 & $50.3(39.5-61)$ \\
$\leq 20$ & 7 & $60.1(52.4-67.8)$ \\
\hline $20-40$ & 6 & - \\
\hline 40 & & \\
\hline
\end{tabular}

Figure 3. H. pylori Prevalence Rate According to the Year of Study and Sample Size
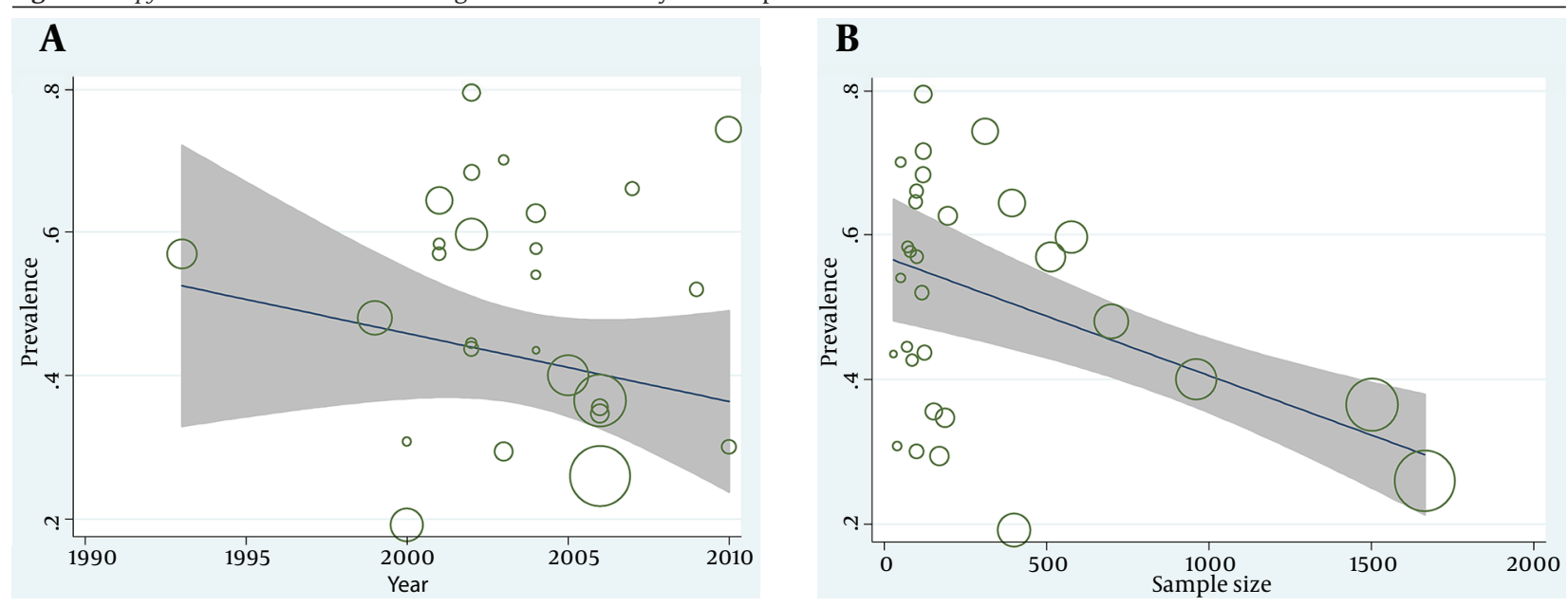

The fitted line show meta-regression line. 
Table 4. The Unadjusted and Adjusted Regression Coefficients and Corresponding P Values for Correlation Between Potential Influential Factors and H. pylori Prevalence Using meta-Regression Models

\begin{tabular}{lcc}
\hline Factors & Regression Coefficients & P \\
\hline Year of data collection & - & - \\
\hline Unadjusted & -0.00332003004 & 0.707 \\
Adjusted & 0.0086586 & 0.21999 \\
\hline Age group & - & - \\
\hline Unadjusted & 0.1077322 & 0.017 \\
Adjusted & 0.1222877 & 0.008 \\
\hline Sample size & - & - \\
\hline Unadjusted & -0.0001338 & 0.060 \\
\hline Adjusted & -0.000919 & 0.159 \\
\hline
\end{tabular}

Table 5. Prevalence Rate of H.pylori in Iran According to City

\begin{tabular}{|c|c|c|c|c|}
\hline City & Random Effects OR, 95\% CI & $\mathbf{I}^{2}, \%$ & Sample Size & Study, No. \\
\hline Kashan & $48.9(14.4-2004.3)$ & 93.8 & 139 & 2 \\
\hline Sari & $41.8(-0.025-0.86)$ & 99.5 & 20004 & 2 \\
\hline Semnan & $48(44.3-51.7)$ & - & 700 & 1 \\
\hline Ghazvin & $61.7(26.6-96.8)$ & 97.4 & 245 & 2 \\
\hline Khorasan Razavi & $48.6(21.3-75.9)$ & 96.9 & 32003 & 2 \\
\hline Tehran & $53.5(39.1-67.8)$ & 98.4 & 3295 & 10 \\
\hline Yazd & $43.5(25.1-61.9)$ & - & 28 & 1 \\
\hline Tabriz & $57.9(45.3-70.5)$ & 86.6 & 418 & 4 \\
\hline Kerman & $56.9(52.6-61.2)$ & - & 513 & 1 \\
\hline Kurdistan & $36.5(34.1-38.9)$ & 73 & 1503 & 1 \\
\hline Isfahan & $36.7(22.6-50.8)$ & 73.4 & 170 & 2 \\
\hline Guilan & $45.3(32-58.6)$ & 97.4 & 1011 & 2 \\
\hline- & $50.7(44.4-56.9)$ & - & 9198 & 30 \\
\hline
\end{tabular}

In a study carried out in Sari in 132001, a significant correlation was reported between the prevalence rate of infection and home ownership and the family size (38). In the study by Azevedo et al. the major risk factors that have been emphasized were the socioeconomic indicators (15).

Among the limitations of the current study, the following can be mentioned: 1) There was not same method to measure variables and diagnostic tests among all studies as well as, 2) The majority of the studies were carried out in a preselected population (blood donors, individuals referring to health care centers and etc.). 3) In most studies, nutritional status and life style were not considered as influencing factors. 4) The range of age groups was considerably wide among different studies.

This study aimed to determine the prevalence rate of H. pylori infection in Iran. Almost half the population in Iran is infected by H. pylori, the prevalence rate being different among different parts of the country. According to the findings of this study, it is suggested that, to prevent the spread of $H$. pylori, comprehensive health programs should be scheduled throughout the country. According to the results of this study, the risk of $H$. pylori infection significantly increases with age, and so, it is recommended that preventive procedures are more seriously followed for high risk age groups. It is also recommended that the ELISA and urease tests are used in diagnostic laboratories to increase the accuracy and perception of diagnostic methods.

Funnel plot (Figure 4) showed the effects of publication bias was significant in this study. Publication bias is very important in randomized clinical trials and case control studies, but it is not important in the meta-analysis that estimates prevalence publication bias. 
Sayehmiri F et al.

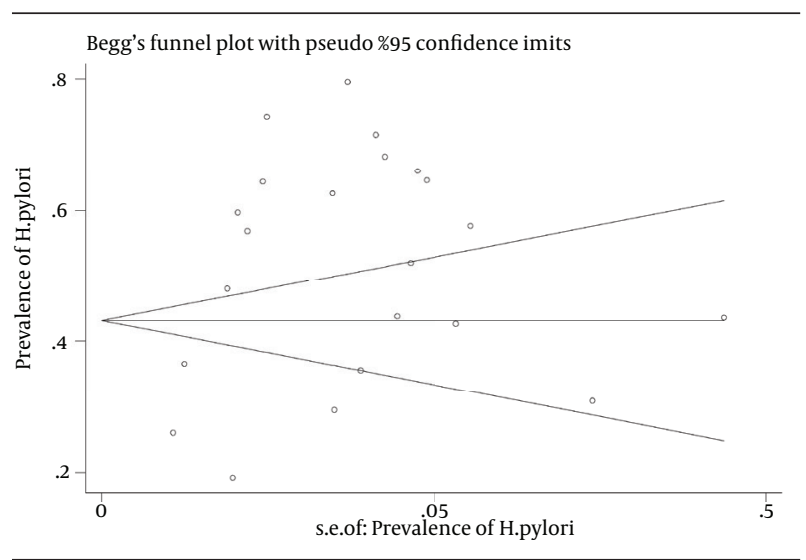

Figure 4. Funnel Plot to Assess Publication Bias

\section{Authors' Contribution}

Fatemeh Sayehmiri and Zahra Darvishi, setareh soroush: Data Collection; Kourosh Sayehmiri: Biostatistic analysis; Mohammad Emaneini and Morovat Taherikalani: study designs; Raffaele Zarrilli: final revision and grammer editing.

\section{Financial Disclosure}

There is no financial interest.

\section{Funding/Support}

This research was done using financial support of student's research committee of Ilam University of Medical Sciences.

\section{References}

1. Bode G, Brenner H, Adler G, Rothenbacher D. Dyspeptic symptoms in middle-aged to old adults: the role of Helicobacter pylori infection, and various demographic and lifestyle factors. $J$ Intern Med. 2002;252(1):41-7.

2. Ortiz D, Cavazza M, Rodríguez O, Hagel I, Correnti M, Convit J. Prevalence of Helicobacter pylori infection in Warao lineage communities of Delta Amacuro State, Venezuela. MOCI. 2003;98(6):721-5.

3. Robin warren J, Marshall B. Unidentified Curved Bacilli on Gastric Epithelium in Active Chronic Gastritis. Lancet. 1983;321(8336):1273-5.

4. Siavoshi F, Malekzadeh R, Daneshmand M, Ashktorab H. Helicobacter pylori endemic and gastric disease. Dig Dis Sci. 2005;50(11):2075-80.

5. Yamada T, Alpers DH, Laine L. Approach to the patient with dyspepsia and related functional dyspepsia in singapor. Singapor Med J.1996;37(4):428-9.

6. International Agency Of Research On Cancer. Schistosomes, Liver Flukes and Helicobacter Pylori. In: Evaluation Of Carcinogenic risk to humans. Geneva; World Health Organization. 1994.

7. Loh KY, Siang TK. Understanding non ulcer dyspepsia. Med J Malaysia. 2008;63(2):174-6.

8. Talley NJ. A critique of therapeutic trials in Helicobacter pylori-positive functional dyspepsia. Gastroenterology. 1994;106(5):1174-83.

9. Lewy-Trenda I, Trenda P, Wierzchniewska A. Non-ulcer dyspepsia and Helicobacter pylori infection-morphological analysis according to the Sydney system-changes before and after treatment. Pol J Pathol.1996;47(2):57-63.
10. Megraud F, Brassens-Rabbe MP, Denis F, Belbouri A, Hoa DQ. Seroepidemiology of Campylobacter pylori infection in various populations. JClin Microbiol.1989;27(8):1870-3.

11. Cullen DJ, Collins BJ, Christiansen KJ, Epis J, Warren JR, Surveyor I, et al. When is Helicobacter pylori infection acquired? Gut. 1993;34(12):1681-2.

12. Wang KJ, Wang RT. Meta-analysis on the epidemiology of Helicobacter pylori infection in China. Zhonghua Liu Xing Bing Xue Za Zhi. 2003;24(6):443-6.

13. Islami F, Kamangar F. Helicobacter pylori and esophageal cancer risk: a meta-analysis. Cancer Prev Res (Phila). 2008;1(5):329-38.

14. Talebi-Taher M, Mashayekhi M, Hashemi MH, Bahrani V. Helicobacter pylori in diabetic and non-diabetic patients with dyspepsia. Acta Med Iran. 2012;50(5):315-8.

15. Azevedo NF, Huntington J, Goodman KJ. The epidemiology of Helicobacter pylori and public health implications. Helicobacter. 2009;14 Suppl 1:1-7.

16. Weyermann M, Rothenbacher D, Brenner H. Acquisition of Helicobacter pylori infection in early childhood: independent contributions of infected mothers, fathers, and siblings. Am J Gastroenterol. 2009;104(1):182-9.

17. Hajagamohammadi AA, Sheikholslami H, Esmaeili R. [Prevalence of Helicobacter pylori infection in different endoscopic lesions of patient in Qazvin Boualisina hospital]. QUMS. 2005;9:8-15.

18. Sheikholslami H, Ghasemibarghi R, Mosavi H. Comparison prevalence of Helicobacter pylori infection in urban and rural areas of Qazvin . GUMS. 2004;8:47-51.

19. Zojajy H. [Prevalence of Helicobacter pylori in patients undergoing upper GI endoscopy in hospital No1, Kerman University of Medical Sciences]. KMUSJ. 1994;1:103-7.

20. Arj A, Ehteram H, Mortazavi T, Taghadosi M, Mousavi GA, Vakili Sohr Foroozani Z. [Efficacy of stool antigen test for the non-invasive diagnosis of Helicobacter pylori infection in dyspeptic patients referred to GI clinic of Kashan Shahid Beheshti Hospital during 2007-8]. KAMUS. 2011;15:17-22.

21. Sanei MH, Mahzouni P. [The role of Helicobacter pylori infection in gastric carcinoma].J Yasuj Univ Med Sci. 2005;10:36-41.

22. Moradi A, Rashidy-pour A. [Seroepidemiology of Helicobacter pylori infection in Semnan]. Koomesh J. 2000;1(4):53-7.

23. Faghihi Kashani AH, Kabir A, Basi A. [Comparison of frequency of Hielicobacter pylori infection subgroup of patients with nonulcer dyspepsia]. Razi J Med Sci. 2003;9:557-66.

24. Yasseri HF. [Determination of Helicobacter pylori prevalence in histologic gastritis and intestinal metaplasia and related to age and sex study on 576 patients with nonulcer dyspepsia at endoscopy department of Firozgar Hospital]. Razi J Med Sci. 2002;9:32000-387.

25. Zamani A, Bahremand S, Ojaghi Haghighi SM, Daneshjou K, Tirgari F, Ghasemi M. [Endoscopic findings in children with Helicobacter pylori infection and abdominal tenderness]. TUMJ. 2008;65(11):60-5.

26. Barati M, TalebiTaher M, Hashemi MH, Boghratian AH, NaserEslami P. [Frequency of $\mathrm{H}$. pylori infection and gastric and duodenal lesions inpatients]. Razi J Med Sci. 2003;35:347-54.

27. Salehi MR, Aboei MS, Ebrahimi A. [Comparative evaluation of Helicobacter pylori in the saliva of patients with periodontal disease and a healthy population by PCR test].JIDS. 2011;6:698-704.

28. Ghanei FM, Asmar M, Amir Mozafari N, Afra A, Geranmayeh S Bagherzadeh $\mathrm{AH}$, et al. Isolation of Helicobacter pylori with PCR method from oral aphthous of patients with recurrent aphthous stomatitis in Rasht In 2002 . GUMS. 2002;13(50):33-8.

29. Gottaslou R, Kazemi B, Megraud F. Value of Urease Test in the detection of Helicobacter pylori infections. JUMS. 2005;2:5-9.

30. Taghavi-Ardakani A, Anvari S, Afzali H, Mosavi GA, Tghadosi M. [ Prevalence of $\mathrm{H}$. pylori in children with chronic stomach ache and efficacy of rapid urease test in their diagnosis]. KAUMS. 2002;2001:13-5.

31. Rafiei M, Nejati N, Gholami N, Majidi H, Jafari JA. [Investigation of coinfection of $\mathrm{H}$. pylori in children and their parents]. TBZMed. 2009;31:31-5.

32. Sharifian SA, Ehsani-Ardakani M], Aminian O, Shakeri M. [Comparison between $\mathrm{H}$. pylori infection among dentistry and pharmacy students of Tehran University of Medical Sciences in 2004]. 
SBMUJ. 2004;30:231-4.

33. Yazdanpanah K, Rahimi E, Afsaneh S, Aishi A. [Epidemiology of H. pylori infections among Kurdistan Province population in 2006]. SJKU. 2009;14(1):1-8.

34. Neshandar-Asl E, Jadiri B, Baladast M, Ehsani-Ardakani MJ, Shafei B, Honarkar Z, et al. [The effect of $\mathrm{H}$. pylori on the gastric emptying changes in patients with non-ulcer dyspepsia]. $S B$ MUJ.2005;28:175-12002.

35. Mansor Ghenaei F, Yousefi Mashhor M, Jokar F, Jamali M, Jafarshad R, Bagherzadeh AH, et al. [The prevalence of H. pylori infection in primary school student in Guilan]. IJID Med.2008;43:63-7.

36. Vahidi S, Azadegan M, Shakeri-Joshaghan A. [Comparison of touch cytology and histopathology in the diagnosis of $\mathrm{He}-$ licobacter pylori infection in gastric biopsy specimens]. SBMUJ.2001;26:241-3.

37. Dolatian M, Nouri-Daloei R, Zojaji H, Alavi-Majd H. [Relationship between Helicobacter pylori infection and anemia in pregnant women].JRI. 2007;86:238-46.

38. Baba mahmodi F, Ajami A, Kalhor M, Khalilian A, Shafiei G. [Seroepidemiological study of H. pylori infection in the city of Sari in 2002]. MazUms. 2005;43:25-7.

39. Tergar Fakheri H, Kosarean M, Mahdavi M, Bahar A, Kamali Z, Esmaeeli MR. [The association between helicobacter pylori and iron stores]. MazUms. 2004;14(45):61-7.
40. Nakhaei moghadam M, Khajeh Karamoldeni M, Malekzadeh F, Fomani Khoshnavaee A. [Prevalence of Helicobacter pylori in gastric biopsy specimens, the sensitivity, specificity and diagnostic techniques].JGUMed Sci. 2005;11(2):37.

41. Benesh F, Rashtian P. [The prevalence of Helicobacter pylori infection in patients with gastric lymphoma pathology referred to yazd city]. JSSUMed Sci. 2006;14:15-22.

42. Baghaei K, SHekarzadeh L, Jafari F, Belfion M, Mashaekhi ZH, Zali MR. [Relationship between the cagA gene of Helicobacter pylori and cagE Iranian patients with gastric problems]. JSBU.2010;15:137-49.

43. Rahnama B, Fatahi E. [Comparison of diagnostic ELISA and urease test for detection of Helicobacter pylori in patients with upper gastrointestinal disorders]. TBZMed. 2002;53:19-23.

44. Rafeey M, Nikosh M. [Helicobacter pylori antigen in stool samples of children with the diagnosis of Helicobacter pylori infection]. EMHJ. 2004;48:21-7.

45. Modaresi Asfh Z, Ostadrahimi AR, Somi MH, Roshangar L, Poorghasem Gargari B, Halimi M. [Strongly associated with Helicobacter pylori infection and dietary habits]. KUMS. 2011;3:186-92.

46. Shokohizadeh L, Mohabati mobarez A, Sadeghi zadeh M, Amini M. [The relationship between Cag A gene in Helicobacter pylori and endoscopic findings]. KMJ. 2006;3:261-6. 